\title{
Galactose Elimination Capacity
}

National Cancer Institute

\section{Source}

National Cancer Institute. Galactose Elimination Capacity. NCI Thesaurus. Code C124342.

A liver function test that measures galactose elimination capacity in a biological specimen. 